\title{
REDE SOCIAL BELA VISTA: ATIVISMOS URBANOS, REDES E DINÂMICAS COMUNICACIONAIS NO BIXIGA
}

\author{
Bela Vista Social Network: Urban Ativism, Networks and communicational \\ dynamics in the neighborhood of Bixiga
}

\begin{abstract}
Rede social Bela Vista: activismo urbano, redes y dinâmicas comunicacionales en el barrio Bixiga
\end{abstract}

\author{
Simone Luci Pereira \\ Professora/Pesquisadora (PPGCOM - UNIP) \\ simonelp@uol.com.br \\ Milena Signor Avelar \\ Pesquisadora - URBESOM (PPGCOM -UNIP) \\ signormila@hotmail.com
}

\section{Resumo}

Apresentamos aspectos da pesquisa em curso sobre o bairro do Bixiga e focalizamos as ações de um grupo/coletivo: a Rede Social Bela Vista. Conjugando formas de atuação em negociação com lógicas institucionais e comunitárias, a Rede articula lógicas e dinâmicas locais/globais que ocorrem no Bixiga, entre empreendedorismos, economias e práticas culturais alternativas e criativas, em seus limites e possibilidades. Após discutir aspectos históricos e o método utilizado (derivas urbanas de inspiração etnográfica), finalizamos com a análise da Rede. Temos como conclusões parciais que suas práticas refletem elementos da comunicabilidade do urbano, articulando ativismos pelo direito à cidade, usos e apropriações dos territórios, lógicas de produção e consumo cultural contemporâneo e cosmopolita, identidades e modos de estar juntos.

Palavras-chave: Bixiga. Ativismo urbano. Território

\begin{abstract}
We present aspects of the current research on the neighborhood of Bixiga and focus on the actions of a group/collective: the Bela Vista Social Network. Combining forms of action in negotiation with institutional and community logics, the Network articules local/global logics and dynamics that occur in the Bixiga, between entrepreneurs, criative economies and alternative cultural practices, within its limits and possibilities. After discussing historical aspects and the method used (urban "dérives" with ethnographic inspiration), we finish with the Network analyses. We conclude that its practices give clues about elements of urban communicability articulating activism for the right to the city, uses and appropriations of the territories, logics of production and cultural consumption and cosmopolitanism, identities and ways of being together.
\end{abstract}

Keywords: Bixiga; Urban activism; Territory 


\section{Resumen}

Presentamos aspectos de la investigación en curso sobre el barrio Bixiga y nos centramos en las acciones de un grupo/colectivo: la Red Social Bela Vista. Combinando formas de actuar en negociación con lógicas institucionales y comunitarias, la Red articula lógicas y dinámicas locales/globales que ocurren en Bixiga, entre emprendimientos, economías y prácticas culturales alternativas y creativas, dentro de sus límites y posibilidades. Después de discutir aspectos históricos y el método utilizado (derivas urbanas de inspiración etnográfica), concluimos con el análisis de la Red. Tenemos como conclusiones parciales que sus prácticas reflejan elementos de comunicabilidad urbana, articulando activismos por el derecho a la ciudad, usos y apropiaciones de territorios, lógicas de producción y consumo cultural contemporáneo y cosmopolita, identidades y formas de estar juntos.

Palabras clave: Bixiga. Activismo urbano; Territorio

\section{INTRODUÇÃO}

Compreender e analisar características existentes no Bixiga, seus múltiplos agentes e suas dinâmicas comunicacionais e interculturais nos permite entender seu lugar como agente atuante nos debates atuais sobre direito à cidade e sobre circuitos de produção e consumo cultural e material. Estas dinâmicas estão diretamente ligadas ao estudo e compreensão da comunicabilidade do urbano, levando em conta a complexidade de seu tecido material, os fluxos de pessoas, imagens, tecnologias, imaginários, culturas e subjetividades.

Neste artigo apresentaremos alguns aspectos de uma pesquisa em andamento sobre dinâmicas culturais/sociais atuais do Bixiga. Apresentamos elementos históricos da região não para compreender relações de causa e efeito ou linearidades temporais, mas para mostrar - esse é o nosso objetivo neste artigo - a complexidade das dinâmicas comunicacionais e interculturais urbanas ali existentes, seus sentidos políticos na atualidade e os usos e apropriações dos territórios. Entre as muitas dinâmicas vistas, destacamos uma nova visibilidade alcançada pelas lógicas de consumo cultural ali colocadas em jogo nos últimos anos: bares e casas noturnas com propostas de música e cultura alternativa imbricadas em ativismos urbanos, culturais e políticos; bares com noites de jazz e vinil; a existência de bares secretos em galerias de arte; a breve existência da Praia da Pipa - primeira proposta de praia urbana em São Paulo; sede de coletivos e ONGs; espaços de coworking; disputas e mobilizações em torno do Parque do Bixiga. Enfim, questões que na contemporaneidade estão na pauta das discussões sobre cidades, bairros e economias criativas em todo o mundo em suas possibilidades, promessas, limites e problemas (SELDIN, 2016; GONÇALVES, 2016). 
Por todas estas questões recentes que vêm dinamizando a região do Bixiga e por interessarmo-nos por compreender sentidos dos ativismos urbanos (sejam mais ou menos assumidos e nomeados pelos atores) na atualidade - os quais conjugam lógicas políticas com lógicas econômicas (vinculadas a temas como economias criativas e bairros criativos), de consumo, de entretenimento, de socialidades - é que esta localidade da cidade nos chama a atenção como objeto de estudo.

Estudar as dinâmicas comunicacionais no Bixiga e alguns de seus agentes é uma forma de compreender um microcosmo dessa imbricação de sentidos, como uma janela etnográfica pela qual se observam muitas outras coisas. A região se apresenta como um exemplo das características de alguns ativismos contemporâneos, em que os sujeitos buscam uma atuação em torno da vida urbana e no direito às cidades, atuando localmente, mas dialogando com questões fluxos e questões globais a todo momento presentes.

Após apresentar algumas questões históricas da formação social e cultural do Bixiga, explicitamos a metodologia que temos adotado na pesquisa sobre a região. A metodologia se baseia na prática das derivas urbanas (CARERI, 2013; FERNANDES E HERSCHMANN, 2015; JACQUES, 2012), com inspiração nas práticas de etnografia urbana que compreendem o caminhar como prática estética e política na busca por uma compreensão corporal e sensível do urbano e seus trajetos, descontinuidades, fragmentos, e também ligações, formas de associação e redes. Na última parte, analisamos a Rede Social Bela Vista, um coletivo em rede que desde 2005 se articula e age para discutir, implementar e realizar ações no Bixiga, relativas à saneamento, meio-ambiente, coleta de lixo, educação, entre outros elementos, e que tem nas ações culturais um elemento de visibilidade.

\section{DESENVOLVIMENTO - DINÂMICAS HISTÓRICAS}

Rolnik (1986) aponta que a formação do Bixiga tem suas bases no fato de se tratar de uma localização onde havia grandes entroncamentos comerciais que foram áreas importantes no processo de desenvolvimento da cidade de São Paulo ainda no século XIX. Pelo fato de se tratar de uma região onde a topografia e a irregularidade do terreno favoreciam que os escravos fugidos se escondessem e a proximidade a um pequeno rio, ali naquele espaço que hoje chamamos de Bixiga, os negros se estabeleceram em torno do primeiro quilombo urbano da cidade, às margens do córrego da Saracura (onde hoje é a Avenida Nove de Julho). Assim, o Bixiga se estabelece como território negro desde suas origens tendo esta presença ainda 
forte e social e culturalmente (Escola de Samba Vai-Vai, Pastoral Afro na Igreja Nossa Senhora Achiropita, para citar apenas alguns elementos mais visíveis).

Rolnik (1986) e Schnek (2016) apontam que o fim da escravidão no final do século XIX, deu lugar a uma nova preocupação para parte da elite paulistana da época: a substituição da mão de obra. Esta preocupação estimulou o processo de imigração que ocorreu no Estado e em todo o país, e favoreceu o deslocamento de milhares de europeus, sobretudo italianos, para as terras paulistas; daí a presença forte deste grupo ainda hoje no Bixiga. A substituição da mão de obra escrava pela mão de obra imigrante veio acompanhada de um discurso que pregava uma solução progressista, na medida em que, além de força de trabalho, a cidade ainda ganharia a cultura europeia no seu desenvolvimento, dentro de uma política de branqueamento da nação típica da virada do século XIX para o XX.

Haesbaert (2012) explica que a noção de território é sempre ligada às dimensões políticas, sendo o resultado de uma disputa de forças pela busca do controle do espaço e ou delimitações de uma área geográfica, envolvendo apropriações que são materiais e simbólicas donde surgem as identidades territoriais, ou seja, a identificação e pertencimento que determinados grupos sociais desenvolvem com os lugares. Podemos perceber esta dimensão simbólica quando consideramos que o Bixiga não existe como bairro nas divisões ou delimitações oficiais da Prefeitura de São Paulo. Área dentro do bairro da Bela Vista, integrante do centro expandido da capital paulistana, corresponde aproximadamente à região localizada entre às ruas Major Diogo, Sílvia, Rui Barbosa, Treze de maio, Avenida Nove de Julho e Avenida Brigadeiro Luís Antônio ${ }^{1}$. Tampouco há algum tipo ou espécie de marcação quanto aos limites das ruas e avenidas do bairro, explicando se aqui ou ali começa ou termina a região do Bixiga. E, tão interessante quanto esta ausência de bordas ou limites, é o fato de quando perguntamos aos moradores, todos afirmam com muita convicção onde se circunscreve o Bixiga. Como lembra Pereira (2017), os territórios não existem em si, mas nos seus usos, forjados pela ação dos grupos no exercício da vida.

Nas décadas de 1950/60, em decorrência de uma corrente de deslocamentos populacionais no Brasil ancorados na transferência de população do meio rural para o meio urbano, os migrantes nordestinos começam a chegar em grande número à cidade de São Paulo, se estabelecendo tanto em regiões mais afastadas das periferias, quanto em regiões centrais. Segundo a historiografia do bairro, dois fatores favoreceram a alta concentração de

1 Possui área de 2,60 km², população de 69.460 pessoas (2010) e densidade demográfica de 26.715 (habitantes $/ \mathrm{km}^{2}$ ). Fonte Prefeitura Municipal de São Paulo. Disponível em: www.prefeiturasp.gov.br. Último acesso em 16/07/2020. 
migrantes nordestinos no local: a proximidade com a Avenida Paulista e com o centro da cidade, o que facilitava a busca por empregos devido às possibilidades de transporte e deslocamento. Acrescente-se a isso a existência dos cortiços, que possibilitavam formas baratas de moradia.

A chegada dos nordestinos trouxe ao Bixiga novas frentes de disputas e negociações nas suas dinâmicas comunicacionais e interculturais. As bases nas tradições afro brasileiras tinham muitas semelhanças ao que era praticado no reduto negro do Bixiga; a capoeira e as rodas de samba, por exemplo, materializam estas semelhanças. Porém, os conflitos também trouxeram à tona discussões, rivalidades e disputas. Conversando com moradores da região que trabalham em um restaurante local, é possível perceber uma dissidência quanto à história oficial do Bixiga edificado como sendo "o bairro mais italiano de São Paulo". Alguns moradores nordestinos da região explicam que não acham tão verdadeiro este slogan popularmente divulgado pelo senso comum e midiaticamente. Os moradores contam que a cozinha italiana do Bixiga tem mais influências nordestinas do que em outros lugares da cidade já que a grande maioria dos cozinheiros dos restaurantes do Bixiga são nordestinos. Fora isso, lembramos ainda da forte presença populacional de nordestinos no bairro com seus negócios locais, bares, botecos, casas de produtos do Norte, a Casa do Mestre Ananias, um centro de tradições baianas, ali estabelecido há décadas.

Essas dissidências apontadas nos trazem a oportunidade de visualizar a noção da cultura como recurso (YUDICE, 2005). Seja "o bairro mais boêmio de São Paulo", seja "o reduto italiano da cidade", a invocação destas máximas criadas pelo senso comum visa atrair visibilidade a uma necessidade econômica e identitária. A cultura como recurso se mostra aí como possibilidade de inserção e cidadania cultural e comunicacional destes grupos, revelando tensões, apropriações, negociações na composição performativa destas identidades.

Um breve relato da composição do Bixiga pelos múltiplos agentes envolvidos e a pluralidade cultural destes nos esclarecem sobre a diversidade cultural ali existente Isso se mostra tanto na maneira de interpretação dos espaços urbanos, no sentido de se transformarem em lugares sociais híbridos, quanto no fato do Bixiga ser exemplo de uma espécie de mosaico de superposições e entrecruzamentos, em que as territorialidades do espaço urbano originam lugares sociais híbridos que, ao invés de possuírem uma identidade única, assumem um caráter fluido, múltiplo, com fronteiras movediças que se penetram e se misturam (PEREIRA, 2017). 
Em decorrência da interculturalidade ${ }^{2}$ (GARCIA CANCLINI, 2007) que compõe o Bixiga, é necessário pensarmos as cidades na conjunção de articulações e disjunções comunicacionais onde as identidades, pertencimentos, afetos, socialidades formas de auto representação se articulam à práticas e imaginários nos quais a dimensão urbana e sua cultura são atravessadas por lógicas comunicacionais que se tornam constitutivas da vida nas cidades.

Após anos de intensa atividade cultural - desde os anos 1950/60 com os inúmeros teatros e restaurantes italianos constituindo uma vida boêmia ligada aos artistas e jornalistas, e depois, nos anos 1980, com a presença de bares e casas de música que reuniu a cena do rock e da música independente daquela década (PEREIRA, 2018) - a partir dos anos 1990, o Bixiga passou por uma fase decadente tendo algumas casas noturnas e teatros fechados e passando a ser ponto de encontro para consumo de drogas e prostituição. Porém, nos últimos anos o Bixiga vem sendo protagonista de um fenômeno bastante interessante sob o ponto de vista social, cultural e comunicacional, permitindo que se perceba um "renascimento" ou talvez uma mutação, pois começa a atrair outros atores, mudando e integrando de maneira distinta e singular o consumo cultural da região, seja nas cantinas já existentes há muitos anos ou em novos bares e espaços que vem apoiando esta nova dinâmica de consumo cultural no local.

Como aponta Pereira $(2017 ; 2018)$, a região do Bixiga vem despertando inclusive o olhar de certo jornalismo cultural que vem chamando a área de "novo bairro hipster" de São Paulo, apontando para a presença de um circuito de produção e consumo cultural e material mais alternativo (seja nas casas noturnas, seja na presença de escritórios de coworking, seja em barbearias "descoladas", lojas de produtos orgânicos e veganos, etc.). Não concordamos com esta categorização hipster para a região, pois esta designação parece muito consoante com realidades do Norte global e suas noções de subculturas, algo que em nossos contextos deve ser utilizado com cautela. Buscamos trazer mais complexidade a estes novos circuitos de produção e consumo cultural/material, compreendendo-os como articulados às lógicas das culturas híbridas latinoamericanas em que elementos da cultura popular se mesclam com lógicas de visibilidade e consumo da cultura midiática, trazendo maior ecletismo de gostos, modas e valores. Mais ainda, salientamos nestas práticas recentes na região do Bixiga a articulação a uma certa (re)valorização das áreas centrais da cidade (PEREIRA, 2017) por grupos que buscam

\footnotetext{
${ }^{2}$ Vale frisar que a noção de interculturalidade apontada por Garcia Canclini mostra-se como um instrumento conceitual e analítico para pensar e interpretar as zonas de contato entre as culturas, estes espaços instersticiais em que as culturas se confrontam, entram em conflito e negociam sentidos. A noção de interculturalidade não deve ser confundida com a noção de multiculturalismo, que já foi bastante criticado por seu caráter acrítico de celebração de diversidade e justaposição "apaziguadora” de culturas diferentes e mesmo por seu caráter liberal.
} 
consumos musicais/noturnos mais alternativos, o que contém sentidos políticos na ênfase que mostram quanto aos usos e ocupações mais democráticas do espaço urbano da cidade.

Após termos apresentado alguns elementos históricos que salientam a interculturalidade no Bixiga bem como sua trajetória de certo polo cultural e noturno da cidade, buscamos enfocar suas dinâmicas recentes. Na próxima sessão, abordaremos aspectos do método utilizado até aqui que nos levou a descobrir mais aspectos do bairro.

\subsection{Derivas urbanas como método}

No decorrer desta pesquisa fomos à campo, redigimos um diário das derivas (caminhadas) realizadas no Bixiga, registro e anotações das conversas informais com os agentes do bairro; participamos das festas de ruas e cursos oferecidos pelos produtores culturais, etc. Tomamos as noções de Restrepo (2016) sobre a prática etnográfica, tendo sempre em conta a importância de descrever os fatos e eventos observados considerando a complexidade das relações entre os múltiplos agentes e o Bixiga.

As derivas urbanas nos convidam a explorar, através de caminhadas pelas cidades, os territórios atuais ou espaços intermediários, que também podemos chamar de espaços do “entre", espaços do meio- lugar (CARERI, 2013). Para Careri, o meio-lugar não é um lugar preciso, nem um não-lugar (no sentido dado por M.Auge), mas a sua prática, a sua apropriação ou o seu uso. $\mathrm{O}$ autor salienta a necessidade de caminhar pelas cidades como prática estética e política que auxilia na compreensão do espaço, da vida urbana e de seus habitantes, numa apreensão do urbano em suas múltiplas dimensões inteligíveis e sensíveis. Ao praticarmos as caminhadas pelos espaços da cidade podemos perceber que apenas pela escala do corpo esta interação e dinâmica ocorre, pois ele atua como um vetor de comunicabilidade entre os sujeitos, o espaço urbano e os ritmos e cadências da cidade (PEREIRA; LÓPEZ MOYA, 2018).

Jacques (2012) detalha os primeiros movimentos na área das Artes e da Arquitetura e Urbanismo que deram início às discussões sobre as errâncias e a cidade. A pesquisadora compara três fases da história da Arquitetura com três formas de resistência a cada uma delas: a flanerie no século XIX, o Dadaísmo e o Surrealismo nas primeiras décadas do século XX e os situacionistas nos anos 1950/60. Em todas essas fases, Jacques coloca a "errância" como valor e meio pelo qual se pode viver a experiência da alteridade nos meios urbanos. Aqui, nos centraremos nos situacionistas. Segundo ela, a base do pensamento situacionista era a 
psicogeografia e a deriva, inspirados na "construção de situações". As derivas seriam então uma técnica de andar sem rumo, de perder-se intencionalmente na cidade, levando sempre em conta a influência do cenário.

As derivas urbanas ou o caminhar pelas cidades são possibilidades de se ver e captar os entre-meios, o que não está explícito. A atuação do corpo se dá como vetor de comunicabilidade entre os sujeitos e o espaço urbano faz com que este ancoramento que se dá e se efetiva na ordem do corpo traga re-significações e atuações como fatores de reconhecimento individuais e coletivos, ocupando e habitando as cidades em suas áreas mais conhecidas, turísticas e movimentadas, como também em suas cicatrizes e em seus espaços vazios (PEREIRA; GHEIRART, 2018).

Somamos aqui dois conceitos: primeiro, as noções apresentadas por Careri (2013) sobre as possibilidades de cartografar as cidades utilizando o caminhar como prática estética (transurbâncias ou derivas). Segundo, o de Fernandes e Herschmann (2015) os quais, no campo da Comunicação, atentam para esta forma de cartografar a cidade como um "mapanoturno" - inspirados por Martín-Barbero (2004) - percebendo as ideologias e as dimensões do poder nos planos urbanísticos e nas regulações das cidades, mas sem perder de vistas as brechas abertas pelos sujeitos do cotidiano. Nesta perspectiva, a precariedade e a subjetividade envolvidas nos trabalhos de pesquisas nos levam a captar não as certezas, mas o que está em ebulição, em emergência, o que não está completamente definido. Esta perspectiva nos auxilia na compreensão das dinâmicas comunicacionais que compõem os fluxos e os nós, os imbricamentos das relações que ocorrem no Bixiga e nas complexidades das relações ali envolvidas.

Quando direcionamos nosso olhar para esta localidade, conseguimos visualizar as oportunidades que os usos das derivas urbanas nos trazem, uma vez que o objetivo central deste trabalho é compreender as múltiplas dinâmicas existentes entre o bairro e seus múltiplos atores/agentes. Jacques (2012) nos explica que nos últimos anos há uma "tendência pacificadora" dos espaços públicos e dos espaços urbanos, relacionada diretamente com os processos de espetacularização das cidades. A autora lembra que esta tentativa de pacificação dos espaços se dá através de fabricações de falsos consensos, do encobrimento dos conflitos e disputas que lhes são inerentes; consequentemente, esta tentativa ocasionaria uma certa esterilização das experiências de alteridade nas cidades. Por conta disto, se torna ainda mais relevante a valorização da alteridade urbana, a valorização do outro urbano que resiste a todo 
este processo pacificador e desafia à construção de todos estes "pseudo consensos" (JACQUES, 2012).

Tomamos então que a prática das derivas urbanas não se constitui num caminhar aleatório, mas não possui planejamentos ou roteiros prévios. Isso nos auxilia neste encontro com a cidade e os seus Outros, e a viver, portanto, a experiência de alteridade na cidade. Associados ao trabalho de caminhar pelas cidades de Careri (2013), Jacques (2012) diz que caminhar pela cidade sem planejamento é um exercício de afastamento voluntário do lugar mais familiar e cotidiano. $\mathrm{O}$ errante vai de encontro à alteridade na cidade, ao Outro, aos vários outros, à diferença, aos vários diferentes. O errante vê à cidade como um terreno de experiências e jogos e além de propor experimentar e jogar, eles também buscam transmitir suas narrativas errantes (JACQUES, 2012). Em consonância com Jacques, acrescentamos que, segundo Fernandes e Herschmann (2015), a proposta de se colocar a deriva não é aleatória, mas corresponde a um método que visa compreender a cidade em sua dinâmica, nas suas atualizações constantes feitas a partir das interações sensíveis e inteligíveis.

As derivas efetuadas pelo Bixiga $^{3}$, nos permitiram apreender o que Canevacci (1997) chamou de comunicação urbana dialógica: em que a arte de se escutar entre duas subjetividades é refinadamente antropológica e só podemos passar à interpretação depois de uma disposição mental interativa, onde acolhemos e solicitamos os murmúrios da cidade.

Para esta pesquisa, muitas derivas foram realizadas no Bixiga e em seus arredores nos anos de 2018 e 2019; algumas com locais e horários definidos para que fosse possível visualizar a ação/atuação de atores específicos que contribuiriam para algum ponto de entendimento. Outras, sem horário e locais definidos, apenas como tentativa de apreensão da região, do que o seu dia a dia cotidiano proporciona aos seus agentes. Em outras derivas, fizemos um percurso diurno pela região, fora do horário comercial das casas noturnas, cantinas e restaurantes, com o objetivo inicial de percebermos o cotidiano do bairro em um horário não destinado a turistas e consumidores. Esta deriva tinha como objetivo visualizar o que Jacques (2012) chama de cidade opaca, longe dos espaços já pacificados, pois é inevitável

\footnotetext{
3 Esclarecemos que frequentamos o Bixiga como pesquisadoras das culturas comunicacionais urbanas interessadas nas dinâmicas atuais daquela localidade e também como frequentadoras de seus locais de produção e consumo culturais alternativos. Como paulistanas e moradoras da cidade de São Paulo, difícil desconsiderar que adquirimos uma memória histórica e cultural que enfatiza a italianidade do bairro e sua vocação como polo cultural e de memória da cidade. Não tivemos a pretensão de neutralizar estas influências em busca de uma análise objetivista e distante, mas incorporá-las e problematizá-las na tessitura da pesquisa de inspiração etnográfica.
} 
comentar que no senso comum uma parte da notoriedade do Bixiga se deu ao longo dos anos por sua vida noturna, como já comentamos.

Em uma outra deriva, no ambiente noturno e boêmio, paramos num bar local, o Al $\mathrm{Janiah}^{4}$ - um equipamento cultural que é bar e ao mesmo tempo espaço cultural, local de resistência política, oferecendo programação distinta como oficinas de arte, idiomas, música, literatura, entre outras coisas - conhecemos uma importante informante, integrante de um grupo de pesquisa sediado na região do Bixiga. Ela, além de nos fornecer dados para nosso trabalho com informações, materiais, bibliografias e documentos sobre a formação da região, ainda contribuiu com relatos sobre o dia a dia e a maneira como os moradores/agentes se relacionam e interagem entre si. Deste encontro, muitos contatos, encontros e visitas foram marcados e realizados, nos dando acesso à uma rede de relacionamentos, interações e socialidades que uma pesquisa à distância certamente teria dificuldades para acessar. O sair à deriva nos possibilitou ver com mais clareza as incongruências, as dissidências e sua complexidade e riqueza de detalhes.

Através da informante já mencionada, ficamos sabendo que havia uma rede ou um grupo formado por moradores e produtores culturais do bairro do Bixiga que militava e atuava pelas causas do bairro. Segundo a informante, a "Rede Social Bela Vista" costuma se encontrar geralmente na primeira quarta-feira do mês e o ponto de encontro é definido previamente e compartilhado em um grupo de WhatsApp. Como já era de conhecimento dela que estávamos pesquisando e estudando o bairro, fomos convidados a participar de uma reunião que aconteceria na semana seguinte, cuja pauta focalizava especificamente um evento importante para o bairro, que aconteceria no mês seguinte.

\subsubsection{A Rede Social Bela Vista}

De uma maneira peculiar os integrantes da Rede Social Bela Vista misturam lógicas de funcionamento e atuação de ONG's, com instituições mais tradicionais, comunitárias e também lógicas ativistas, articulando inciativa privada, setor público e organizações sem fins lucrativos. Rocha e Pereira (2017) explicam que as crenças dos coletivos, a celebração do encontro entre amigos ou desconhecidos, está vinculado ao modo como compreendem o projeto de sociedade que desejam construir, constituindo práticas que são interessadas, afetuais e implicam em ações cotidianas.

\footnotetext{
${ }^{4}$ Disponível em: https://www.aljaniah.com.br/. Último acesso em 16/05/2020.
} 
Dialogamos aqui com as noções de Harvey (2014) quando afirma que o direito à cidade é entendido, simultaneamente, como uma queixa e uma exigência. A queixa seria com relação às condições desfavoráveis ao pleno desenvolvimento da vida cotidiana. A exigência, de que a partir de um novo olhar e novas práticas urbanas, é possível criar alternativas para uma vida cotidiana "menos alienada, mais significativa e divertida" (HARVEY, 2014, p. 11).

Ao escolhermos a Rede Social Bela Vista como foco de análise, levamos em conta o fato de ela ser um nó de uma rede de redes (MARINO, 2016), um coletivo de coletivos com muitas articulações reticulares que se desdobram em outras vinculações e colaborações com outros grupos, ONGs e causas. Ora, esta parece ser uma característica importante e marcante de muitos ativismos atuais, no século XXI. Como nosso interesse desde o início era o de compreender como se esboçavam os sentidos comunicacionais e políticos que as formas de viver e atuar culturalmente na região do Bixiga na atualidade, as atividades e controvérsias (LATOUR, 2012) vistas na Rede nos pareceram adequadas.

A Rede é formada por comerciantes, moradores, responsáveis por coletivos, produtores culturais ou mesmo simpatizantes que se reúnem mensalmente para tratar assuntos em comum do bairro do Bixiga. Entre os integrantes estão representantes da Escola de Samba Vai-Vai, donos de bares, donos de cantinas italianas, representantes de coletivos LGBTs e outros, abrangendo certa diversidade de etnia, gênero, classe social e geração, agrupando negros, brancos, descendentes de italianos, mulheres e homens cis e trans, senhoras da velha guarda da Vai-Vai e moradoras do bairro há muitas décadas até jovens ativistas culturais recém-chegados no bairro, moradores de classe média alta, trazendo uma heterogeneidade para Rede. Esta mesma heterogeneidade também gera conflitos, disputas e negociações que pudemos observar em alguns momentos, constituindo uma espécie de esfera pública de diáspora - para usar o termo de Appadurai (2005) - em que grupos sociais e culturais de diferentes trajetórias, interesses, visões de mundo e até origem étnica e nacional negociam sentidos e espaços dentro dos projetos e ações da Rede como fruto da interculturalidade ali experimentada. Discutiremos mais aspectos desta questão à frente.

As reuniões acontecem preferencialmente na primeira quarta-feira de cada mês e os locais para estas reuniões variam: o Museu do Bixiga, a unidade do SESC na Bela Vista ou a sede de algum coletivo ou ONG. Salientamos que a Rede Social Bela Vista possui um site ${ }^{5}$ também está nas principais plataformas das redes sociais, com perfis no Facebook e

\footnotetext{
${ }^{5}$ Disponível em http://www.redesocialbelavista.com.br/ Último acesso em 09/03/2020.
} 
Instagram (usados para divulgar ações pontuais ou as datas e horários dos encontros), mas usam preferencialmente o grupo de WhatsApp para a comunicação entre os membros.

A metodologia de análise consistiu em seguir os atores em suas associações (Latour, 2012), compreender como se associam, como mantem ou não estas vinculações, as controvérsias que aí surgem, os conflitos, negociações que se perfazem nesta forma de ativismo ao mesmo tempo urbano e cultural, mas sempre com sentidos políticos. Ao seguir estes atores, participamos de reuniões presenciais da Rede, acompanhamos e analisamos seu website e as redes sociais utilizadas, como a página no Facebook, no Instagram e o grupo do WhatsApp. Acompanhar este movimento dos atores entre o espaço urbano e a internet (MIGLIANO, 2020) nos possibilita compreender caminhos, bifurcações, novas associações que vão se montando e desmontando de maneira dinâmica.

Em seu website, a Rede explica que foi criada em 2005 com o objetivo de "promover um modelo de desenvolvimento sustentável da região por meio da articulação e fortalecimento de organizações sem fins lucrativos, governo e iniciativa privada para a mobilização de recursos financeiros, humanos e materiais em prol da comunidade local”6. Ou seja, infere-se que há uma preocupação ampla por questões da região que incluem saúde, educação, saneamento, segurança, mas que têm na cultura e nas atividades culturais uma forma de visibilidade e promoção de integração entre os membros.

Neste artigo fazemos uma análise de questões observadas em reuniões e outros eventos da Rede nos anos de 2018 e 2019. Acompanhamos uma reunião em abril de 2018 (nossa primeira presença na Rede) em que o assunto principal da pauta seria a organização do evento "13 na Treze", isto é, uma festa na Rua 13 de maio (uma das principais do bairro) no dia 13 de maio, que marca no Brasil a data de Abolição da Escravatura, ocorrida em 1888. Entretanto, ainda que este fosse o assunto principal da pauta, muitos outros temas e assuntos foram tratados, nos possibilitando um conhecimento mais amplo das atividades, interesses e focos da Rede, que se desdobraram na análise de outros aspectos do grupo/coletivo analisado (mesmo aqui neste artigo), ajudando-nos a compreender melhor a complexidade de suas ações e das controvérsias e heterogeneidades ali presentes, seja nos interesses de ação, seja nas identidades dos diferentes sujeitos dentro da Rede.

O Museu Memória do Bixiga, local que abrigou a reunião mencionada, é sediado em um imóvel que no passado foi uma residência. A princípio a fachada antiga (parecida com

\footnotetext{
${ }^{6}$ Disponível em: http://www.redesocialbelavista.com.br/Estrutura/Principal/QuemSomos.aspx. Acesso em 09/03/2020.
} 
outras casas do bairro e da rua, naquela data, sem nenhuma identificação), deixava dúvidas se ali era uma residência ou um estabelecimento comercial. Como o portão estava aberto, entramos e em nossa direção veio um senhor que se apresentou como um dos responsáveis pelo museu e imediatamente nos perguntou de onde éramos. Respondemos que havíamos sido convidados por um dos integrantes do Instituto Bixiga, que havia comentado que hoje aconteceria uma reunião da Rede. De maneira muito tranquila e aparentemente "habituado" em lidar com "visitas", o senhor me respondeu que ainda estava terminando de arrumar o espaço para a reunião e que naquele momento não poderia nos dar atenção, mas que ao final conversaria conosco e tiraria nossas dúvidas.

Em um dos cantos da sala, havia placas e totens de uma exposição sobre um músico já falecido, que havia sido doada pela família, ainda moradora do bairro do Bixiga. No outro canto, uma fotografia do bairro da Bela Vista, em preto e branco, tirada de uma perspectiva aérea, medindo aproximadamente 1 metro de largura por 1,50 metro de altura. Era possível perceber um pontilhado feito com uma caneta marca texto de cor escura, que dividia a fotografia de ponta a ponta. Perguntamos ao senhor que organizava as cadeiras se ele podia nos explicar o que significava aquele pontilhado e prontamente ele respondeu que a marcação se referia à área do Bixiga, acrescentando ainda que "ali" todo mundo sabe onde começa e termina o bairro.

Próximo ao horário marcado para o início da reunião, o número de pessoas que chegava aumentou e era possível perceber que elas já vinham conversando da rua ou estavam aguardando na calçada em frente ao museu. As pessoas iam chegando e se cumprimentando com um relativo entusiasmo e intimidade, confirmando que a grande maioria dos participantes já se conhecia e era perceptível que os participantes sabiam quem estava ali pela primeira vez. Sentamo-nos nas cadeiras mais atrás do círculo formado, para evitar chamar atenção e ganhando propositalmente um bom ângulo de observação. Com a sala cheia, a reunião começou.

Quem deu início à reunião foi uma moça jovem, por volta dos seus trinta anos, gestora e uma das coordenadoras da Rede. Era visível que ela conhecia cada um dos participantes que já faziam parte do grupo, e que estava curiosa em conhecer as pessoas que estavam ali pela primeira vez. Ela sugeriu que cada um se apresentasse para que todas as pessoas soubessem quem e porque estavam ali. A jovem sugeriu que o primeiro a falar fosse o senhor responsável pelo museu. 
Ele então começou explicando que era amigo do sr. Armandinho do Bixiga, morador do bairro que no início da década de 1980 - após perceber que com a chegada massiva dos nordestinos ao bairro, as tradições e hábitos da cultura italiana estavam se perdendo - decidiu mobilizar a vizinhança para que fosse fundado um museu que preservasse a memória dos italianos, os quais participaram da criação do Bixiga. O responsável explicou que na década de 1990 se iniciou o processo de "institucionalização" do museu. O processo estava há alguns anos em trâmites judiciais, em busca da regularização documental e tributária do imóvel, pois somente com toda a documentação regularizada o museu poderia ser reaberto. Isso de fato ocorreu meses após a primeira reunião da qual participamos.

Como já apontamos, os italianos não foram os únicos responsáveis pela formação do bairro do Bixiga. A comunidade negra já estava ali e permanece até hoje, contribuindo ativamente com elementos culturais que foram estruturais para a formação do bairro e que trazem muita visibilidade ao local. Por quais razões, a chegada massiva dos nordestinos ao bairro, gerou a necessidade da criação de um museu destinado a "permanência da cultura e das tradições italianas"? Esta busca por criar um museu, um "lugar da memória" (NORA, 1993) do bairro mostra os anseios do presente e de uma suposta fragmentação da região (pela presença de outros moradores) e daí a busca por conservar suas tradições e "verdadeiras origens”, como uma forma de legitimar a cultura italiana que já era conhecida na cidade de São Paulo. Ora, se revelam aí disputas de sentidos pela formulação de uma memória supostamente mais legítima do Bixiga, alertando-nos para o que Hall (2015) aponta sobre a invenção de passados, de tradições, de nacionalidades, como um constructo que diz mais respeito ao presente que ao passado. A busca pela criação de lugares da memória (NORA, 1993) revela a vontade de criar tradições devido à aceleração da história, mas também pela vontade de cristalizar alguns elementos memoriais que se quer legitimar e afirmar, onde a memória se mostra em sua face dinâmica entre lembranças e esquecimentos, naquilo que se quer e se permite lembrar e esquecer, numa disputa simbólica pela apropriação mais legitima e aceita sobre o que seja o a "real" história do Bixiga, em que o passado é usado como fonte para buscar outorgar sentidos e necessidades do presente.

Retornamos ao relato da reunião de abril de 2018. A jovem moradora e coordenadora dos trabalhos da Rede deu início à reunião explicando como seria a dinâmica de apresentações e qual o propósito específico daquele encontro. Explicou que a reunião seria para discutir assuntos relacionados ao evento "13 na Treze", que aconteceria no mês seguinte (maio de 2018), e que seria utilizado para que todas as entidades e associações do bairro 
pudessem mostrar seus trabalhos e fortalecer os vínculos com a comunidade. Nas palavras da jovem, “'O 13 na Treze' funcionaria como um termômetro para avaliarmos as coisas que estão acontecendo no bairro", pois durante o dia várias entidades se apresentariam e isso traria visibilidade ao Bixiga. Rocha e Pereira (2017) explica que nas práticas ativistas os grupos estão atentos às brechas (na cidade, na mídia de massa, nas redes sociais) buscando certa reinvenção dos espaços públicos, acionando para tanto seus modos particulares de estar juntos, de habitar a cidade, de se informar e de se divertir.

Um encontro mensal para tratar assuntos de ordem coletiva e, mais precisamente neste encontro do qual participamos, para planejar e organizar um evento que objetivava ser um "termômetro", reafirma um específico e próprio modo ativista de fazer e viver do Bixiga e mais especificamente da Rede Social Bela Vista, em que sentidos lúdicos e festivos não se separam de sentidos políticos e de lógicas dos consumos culturais contemporâneos, como se pôde perceber nas falas e ações de outros agentes atuantes na Rede. Nesse sentido, nos é útil o argumento de Yudice (2005) quando lembra que cada vez mais a cultura pode ser utilizada para resolver problemas sociopolíticos, como por exemplo, a intolerância e diversidade, quanto para ser um instrumento que impulsiona o crescimento econômico e a geração de emprego.

Ainda na discussão sobre o "13 na Treze", a coordenadora da reunião afirmou que ele seria usado para que todas as entidades e associações do bairro pudessem mostrar seus trabalhos e fortalecer os vínculos com a comunidade. Naquela reunião, diversas ações foram programadas para que ocorressem no evento: a participação da Escola de Samba Vai-Vai e da Bateria 013 (dissidência da Escola de Samba); a lavagem da Escadaria do Bixiga (escadaria construída em 1929, símbolo do bairro, que liga a Rua dos Ingleses e a Rua 13 de Maio) e da Rua 13 de Maio, encabeçada pelo grupo Ilu Obá de Min; um “espaço LGBT” com atividades artísticas, culturais, plantão jurídico, questões de saúde e testagem promovida pelo coletivo LGBTQI+ "Efeito Borboleta"; atividades lúdicas para crianças na Pça. Dom Orione realizadas pelo Colégio Maria José; apresentação de capoeira pelo pessoal da Casa do Mestre Ananias em homenagem ao grupo Quilombolas de Luz; oficinas de teatro e cinema realizadas por diferentes coletivos e parceiros da Rede.

Estas atividades de fato ocorreram no evento do dia 13 de maio daquele ano, um domingo, com ampla participação de moradores do bairro e de outras localidades da cidade, atraídos pelas atividades ali realizadas. Em sua oitava edição em 2018, o "13 na Treze" daquele ano teve como tema "Bixiga, um grito de alerta", enfatizando o caráter de resistência 
e de luta por sobrevivência cultural do bairro e dos grupos que o compõem. Importante salientar que, dentro da Rede, a italianidade reivindicada e buscada (como narramos acima) cede espaço também em muitos momentos para a reinvindicação da negritude inerente ao bairro, em suas tradições, datas comemorativas, criando uma espécie de sincretismo negroitaliano que por alguns momentos parece apaziguar e neutralizar os conflitos e disputas. No evento "13 na Treze" isso ficou bastante perceptível. Nos discursos da Rede é enfatizada a pluralidade racial/étnica do bairro, salientando a característica multicultural da região e de sua representatividade dentro da própria Rede. E no próprio evento, as questões ligadas à negritude foram o foco central, salientando inclusive a crítica à comemoração do 13 de Maio e a problematização da questão da Abolição da Escravatura e da forma como ela ocorreu no Brasil. Entretanto, na reunião citada para a preparação do evento, uma tensão maior era observada entre integrantes mais idosos e tradicionais do bairro (brancos e negros) em relação à presença e destaque de um espaço LGBTI aberto (e não "fechado numa tenda", como sugeriu uma senhora) no evento, sendo que aconteceria durante o dia e com muitas crianças presentes. Estes conflitos e disputas puderam ser percebidos em reuniões e eventos da Rede, demonstrando as dificuldades e desafios experimentados por agrupamentos plurais, heterogêneos e representativos de diversas minorias em forma de democracia radical e plural (MOUFFE, 2003) e não apaziguadora de conflitos ou criadora de falsas harmonias e consensos desde cima (nos moldes liberais clássicos).

A questão étnica, sempre presente nas disputas de sentido no Bixiga, perdeu espaço, ao menos naquele momento, para as questões ligadas ao gênero e à sexualidade e que não deixam de ser também questões geracionais. Nas ações e acontecimentos dentro da Rede Social Bela Vista podem ser percebidas os desafios das formas democráticas e plurais de ativismo, das lutas comunitárias por causas comuns que esbarram em estigmas, preconceitos, não alteridade. E podem revelar também formas novas de contornar, explicitar e reafirmar a diferença no meio das lutas ativistas, comunitárias e urbanas no Bixiga. Não em formas assimilacionistas clássicas, apaziguadoras e encobridoras da diferença, mas em formas que explicitam os conflitos e garantem a legitimidade, representatividade, voz e a escuta de falas e narrativas subalternizadas. No evento, o espaço LGBTI organizado pelo coletivo Efeito Borboleta (que milita pelo empoderamento trans) ocorreu, em parceria com a Coordenação de Políticas para LGBTI da Secretaria Municipal de Direitos Humanos e Cidadania da cidade de São Paulo, salientando a importância da presença e da visibilidade desta causa. Esta presença enfatizava ainda o fato de que o Bixiga não é só italiano e não é só negro, identidades já 
reivindicadas e assumidas pela região, mas é também LGBTI, numa ênfase à interseccionalidade das identidades e das lutas.

Outros assuntos na reunião nos chamaram a atenção sobre as dinâmicas e questões presentes no Bixiga na atualidade. Naquela reunião de abril de 2018 e também em outra que acompanhamos no segundo semestre do mesmo ano, a intervenção de uma moradora do bairro nos chamou a atenção. Ela relatava ser moradora do bairro há mais de 20 anos, explicando que estava participando das reuniões principalmente para dividir uma dificuldade que vinha passando e que ela acreditava ser de interesse de toda a comunidade do bairro. Ela explicou que em sua residência havia criado um projeto chamado de "casa rural no urbano" e locava quartos à turistas e estudantes que procuravam se hospedar na região. Nas redes sociais encontramos o projeto mencionado ${ }^{7}$ na plataforma AirBnb, se apresentando como possibilidade de conciliar a dinâmica urbana e o sossego da natureza. Esta senhora informava ter uma nascente do Rio Saracura (já canalizado há décadas) em sua propriedade, um jardim comestível e que realizava o manejo dos resíduos. O espaço por ela criado se denomina um espaço de contato com o ativismo socioambiental e cultural da cidade, ainda mais por estar no Bixiga próximo a espaços culturais, opções gastronômicas variadas e acesso fácil à Av. Paulista e ao Metrô.

Chamamos a atenção aqui para uma maneira de utilizar e conjugar questões culturais e econômicas, pois ficou clara a preocupação com as questões ambientais, mas a "propaganda" da proximidade à um $h u b$ de gastronomia, cultura e lazer, supostamente traria uma visibilidade comercial. Ela se apresentou como arquiteta aposentada e possuidora de um foco e interesse na preservação de áreas verdes e pelos espaços ameaçados, em geral pela especulação imobiliária. Ela também atua no Projeto do Parque Augusta ${ }^{8}$ e, conforme suas próprias palavras, "vivia atualmente o Projeto do Parque Bixiga". Conta com um parceiro de ativismo nos parques e vem buscando apoio para embargar uma obra na Rua Joaquim Eugenio de Lima (na parte mais elitizada da Bela Vista), em uma residência também tombada, que vem sofrendo uma reforma irregular. Contou que já havia encaminhado pedido de apoio à vereadores que militam por causas verdes e questões ambientais e estava

\footnotetext{
${ }^{7}$ Disponível em: www.airbnb.com.br/rooms/16189077. Último acesso em: 25/02/2020.

${ }^{8}$ Desde a década de 1970, um terreno com aproximadamente $24.600 \mathrm{~m} 2$, localizado na confluência das ruas Augusta, Caio Prado e Marquês de Paranaguá era o motivo de embates judiciais. De um lado grandes construtoras que almejavam construir um complexo de torres residenciais. Do outro, indivíduos, coletivos e associações que defendiam a constituição de um parque. Em agosto de 2018 a justiça foi favorável às questões sociais-ambientais e o terreno passou a ser um bem público comum. Disponível em: https://www.archdaily.com.br/br/900128/sao-paulo-ganha-o-parque-augusta-finalmente. Último acesso em: 24/06/2020.
} 
chamando a atenção para a maneiras com que as grandes empreiteiras vinham agindo no bairro, em processos de gentrificação (GONÇALVES, 2016).

Esta questão da gentrificação e da especulação imobiliária na região da Bela Vista mostrou-se como uma questão abordada em diferentes momentos. Ela se articula à preocupação pelo direito à cidade, às questões ambientais e aos recursos verdes da região, como abordado pela moradora que enfatiza o "rural no urbano", revelando sentidos de estilos de vida alternativos que podem ser pensados e esboçados para a vida urbana. Estas questões surgiram nas reuniões e mostram-se articuladas a esta questão da sustentabilidade e modos de vida alternativos. Nos anos de 2018 e 2019 os moradores do bairro articulam manifestações contra uma questão específico dentro desate quadro maior de preocupações: as disputas em torno do Parque do Bixiga. Com a participação da sociedade civil, estabelecimentos culturais e comerciais do bairro lutaram na justiça contra a construção de torres residenciais de alto padrão, projeto do Grupo Silvio Santos, em um terreno vizinho ao Teatro Oficina ${ }^{9}$, no qual se planteou a constituição de parque. A questão da gentrificação e verticalização do bairro esteve presente como preocupação também no evento "13 na Treze", com a discussão sobre o Parque do Bixiga em um dos ciclos de debates que ocorreu naquela ocasião. As discussões em torno do Parque do Bixiga revelam um engajamento dos moradores e simpatizantes da região com a questão ambiental, da necessidade de áreas verdes e do cuidado com o processo de verticalização que traria uma explosão demográfica ainda maior para o bairro que já é bastante povoado, aumento do número de automóveis, etc. Preocupações que se mostram em diálogo com movimentos ambientais e urbanísticos em várias cidades do mundo (cidades mais caminháveis, para as pessoas, com espaços verdes e públicos, etc.,) e que no Bixiga se complexificam ainda mais com as questões locais/regionais vividas pelo bairro.

Em visitas e participações em eventos do bairro, foi possível identificar que a luta em prol da construção do Parque é unânime, mas esta unanimidade não permanece quando em rodas de conversas os moradores se questionam quanto à gestão e administração do Parque e quanto à uma suposta distância do grupo Teatro Oficina quanto aos interesses mais gerais do bairro. Mas rapidamente chegou-se a um consenso de que "neste momento" a conquista do Parque seria uma vitória de todos, e o que virá depois serão pautas para outras reuniões. Os interesses divergentes, contrários, contraditórios entre os integrantes da Rede cedem espaço

9 O Teatro Oficina Uzyna Uzona, é uma companhia de teatro brasileira, fundada em 1958 e localizada no Bixiga, ao lado de um terreno de aproximadamente onze mil metros quadrados, propriedade do Grupo Silvio Santos. Disponível em: http://teatroficina.com.br/uzyna-uzona/. Último acesso em: 16/07/2020. 
também, em vários momentos, para que o agente/amigo ou morador ao lado, exponha suas reinvindicações e o ativismo pelo bem em comum - o bairro - não saia inteiramente do foco ou perca visibilidade.

Vai se esboçando nas ações dos integrantes da Rede um ativismo que é cultural, social, urbano, tem dimensões afetuais e também econômicas, diretamente ligado às questões que dizem respeito aos usos dos espaços da cidade, sua sustentabilidade e sua ocupação. Este ativismo, geralmente perceptível no momento em que disputas e negociações estão em foco, é uma característica latente dos agentes envolvidos nas dinâmicas comunicacionais no Bixiga e nos permite afirmar que tais disputas e conflitos também fortalecem as fibras do tecido social que ali existe.

O viés ativista percebido na Rede pode ser visto em muitos dos agentes do bairro, independente de idade, gênero, classe social. O ativismo presenciado ali é um ativismo que faz parte de um certo estilo de vida, visível no momento em que ele está em ação, mas também presente nas questões do dia-a-dia, salientando uma certa politização do cotidiano, em que o domínio do político escapa das esferas institucionais e formais e alcança aspectos da vida de todo dia. Concordamos com Rocha e Pereira (2017) quando afirmam que as práticas ativistas são definidas pelos próprios sujeitos que nelas atuam por suas características horizontais e pela consciência das disputas de poder, incluindo as que se dão em torno das possibilidades de enunciação (ROCHA; PEREIRA, 2017), construção e afirmação de identidades e negociações por hegemonia. Esta politização do cotidiano, expressa na luta por causas diversas, em ações coletivas e decisões comunitárias, a busca por horizontalidade nas decisões das pautas, projetos e ações da Rede, parece construir os sentidos ativistas que ali percebemos e que constroem maneiras democráticas dos ativismos e resistência persistirem.

\section{CONSIDERAÇÕES FINAIS}

Buscamos neste artigo apresentar algumas questões que temos percebido e analisado nesta pesquisa ainda em curso sobre a articulação - na região do Bixiga - entre suas práticas culturais, circuitos de produção e consumo cultural e material e os ativismos urbanos e políticos aí envolvidos.

O uso das derivas etnográficas como um método parece possibilitar compreender como as dinâmicas comunicacionais ocorrem, podendo participar dos "making-offs", os processos, as emergências e observando quem são os agentes envolvidos e como atuam. Nestas ocasiões de pesquisa, foi possível verificar que os moradores da região se ajudam 
mesmo sem ter um envolvimento "institucional" entre os agentes em questão. Por exemplo, mesmo sem ser participante das atividades da Casa do Mestre Ananias ou sem ser um capoeirista ou nordestino, é possível encontrarmos moradores do bairro não só participando das atividades ou eventos propostos pela Casa, mas colaborando com os preparativos e com a organização dos eventos. Esses agentes atuam em uma rede interligada e super conectada de maneira rizomática ajudando a conformar aquilo que Caiafa (2017) chama de comunicação urbana.

Questões analisadas nas atividades da Rede Social Bela Vista nos apontam também para alguns sentidos das formas de ativismo contemporâneo, em que, mais do que um ativismo ou militância com o objetivo de uma mudança social macro ou estrutural, os agentes do Bixiga demonstram novas maneiras de fazer política no cotidiano e de se viver no urbano. Vemos aqui a pertinência do argumento de Harvey (2014) ao explicar que somente quando tivermos o real entendimento de que quem constrói e mantem a vida urbana tem uma exigência fundamental sobre suas produções e que uma delas é direito inalienável de criar uma cidade mais em conformidade com seus verdadeiros desejos, é que chegaremos a uma política do urbano que venha a fazer sentido. Segundo os moradores do Bixiga, além de visibilidade, os eventos pelas ruas do bairro também servem como termômetros para que eles consigam perceber e captar os acontecimentos e dinâmicas no bairro.

Outro ponto a destacar seria a questão do uso da cultura como recurso e sua conveniência, salientados por Yudice (2005). Para ele, o uso da cultura pelos atores envolve planejamento, gestão, divulgação enfim, um ecossistema do campo cultural. Nas atividades da Rede e de seus muitos coletivos que ali se conectam, percebemos este uso da cultura como forma de visibilidade, fortalecimentos das fibras do tecido social (YUDICE, 2005), na medida em que assumem-se como sujeitos que perfazem sua atuação entre muitas vozes e interesses, seja as da inciativa privada, do Estado, das ONGs, construindo seu espaço de atuação na negociação entre lógicas mais liberais de incremento à cultura e lógicas mais alternativas a isso, mais colaborativas, e até comunitárias. Utilizam-se, assim, de táticas e astúcias (CERTEAU, 1994) como maneira de encontrar brechas frente às forças hegemônicas, uma vez que o grupo de moradores e agentes culturais consegue, através de eventos e encontros apoiados no uso da cultura, criar formas e mecanismos de visibilidade para conquistarem aliados, defensores e simpatizantes (de fora do Bixiga) de suas causas. 


\section{REFERÊNCIAS}

APPADURAI, Arjun. Dimensões culturais da globalização. Lisboa: Ed. Teorema, 2005.

CAIAFA, Janice. Apresentação ao Dossiê Comunicação Urbana. Revista EcoPós. v. 20, n.3, 2017. p. $1-9$.

CANEVACCI, Massimo. A cidade polifónica: ensaios sobre a antropología da comunicação urbana. São Paulo: Studio Nobel, 1997.

CARERI, Francesco. Walkscapes: o caminhar como prática estética. São Paulo: Ed. G.Gilli, 2013.

CERTEAU, Michel de. A invenção do cotidiano 1. Artes de fazer. Petrópolis: Vozes, 1994.

FERNANDES, Cintia; HERSCHMANN, Micael. Usos da cartografia nos estudos de comunicação e música. Fronteiras - Estudos Midiáticos. v.17, n.3, 2015. p.290-301.

GARCIA CANCLINI, Nestor. A Globalização imaginada. São Paulo: Iluminuras, 2007.

GONÇALVES, Claudia. Intervenções contemporâneas no Bixiga: fissuras urbanas e insurgências. Dissertação de Mestrado em Arquitetura e Urbanismo. Instituto de Arquitetura e Urbanismo Universidade de São Paulo. São Carlos/SP. 2016. 442 p.

HAESBAERT, Rogerio. Territórios alternativos. São Paulo/Rio de Janeiro: Contexto/Ed.UFF, 2012.

HARVEY, David. Cidades Rebeldes: do direito a cidade a revolução urbana. São Paulo: Martins Fontes, 2014.

HALL, Stuart. Identidade Cultural na Pós Modernidade. Rio de Janeiro: Lamparina, 2015.

JACQUES, Paola. Elogio aos errantes. Salvador: EDUFBA, 2012.

LATOUR, Bruno. Reagregando o social: uma introdução à teoria do ator-rede. Salvador: EDUFBA, 2012.

MARTÍN-BARBERO, Jesús. Ofício de cartógrafo: travessias latino-americanas da comunicação na cultura. São Paulo: Loyola, 2004.

MARINO, Aluísio. Cultura, Periferia e direito à cidade: coletividade em São Paulo e Bogotá. Revista Políticas Públicas \& Cidades. v.3, n.3, setembro/dezembro. 2016. p.4-25.

MOUFFE, Chantal. Democracia, cidadania e a questão do pluralismo. Florianópolis: UFSC. Revista Política \& Sociedade. n.3. 2003. p. 11-26. Disponível em:

https://periodicos.ufsc.br/index.php/politica/article/viewFile/2015/1763 Acesso em 20/07/2020.

NORA, Pierre. Entre Memória e História: a problemática dos lugares. Revista Projeto História. São Paulo, PUC/SP. 1993.

PEREIRA, Simone Luci. Alternativos, autorais, resistentes: coletivos musicais, festas e espaços de música em São Paulo. In: Fernandes, Cintia; Herschmann, Micael (orgs). Cidades musicais: comunicação, territorialidade, política. Porto Alegre: Ed. Sulina, 2018. 
PEREIRA, Simone Luci. Circuito de festas de música "alternativa" na área central de São Paulo: cidade, corporalidades, juventude. FAMECOS - mídia, cultura, tecnologia. v.24, n.2, 2017.

PEREIRA, Simone Luci e GHEIRART, Oziel. Coletivos de música eletrônica em São Paulo: usos da cidade, culturas juvenis e sentidos políticos. E-compós. v.21, n.3. 2018.

PEREIRA, Simone Luci; LÓPEZ-MOYA, Martín. De músicas, sons e dissonâncias: experiências de pesquisa nas ruas de duas cidades. Trabalhado apresentado no GP Comunicação e Culturas Urbanas do $4^{\circ}$ INTERCOM - Congresso Brasileiro de Ciências da Comunicação. Anais.... Joinville/SC: INTERCOM, set/2018. Disponível em: http://portalintercom.org.br/anais/nacional2018/resumos/R13-1228-1.pdf Acesso em: 15/07/ 2020.

RESTREPO, Eduardo. Etnografia: alcances, técnicas y éticas. Bogotá: Envión eds, 2016.

ROCHA, Rose de Melo; PEREIRA, Simone Luci. Ativismos juvenis como artesania de uma outra democracia: comunicação, consumo e engajamento político. Comunicação \& Sociedade. v. 39 n. 3. 2017. p.161-188.

ROLNIK, Raquel. Territórios negros em São Paulo: uma história. Folha de S. Paulo, São Paulo, 28 set. 1986. Disponível em:

https://acervo.folha.com.br//leitor.do?numero=9639\&anchor=4304571\&pd=4cb5371f21 c059072e30d 8ef82f87103. Acesso em: 10/05/2019.

SCHNECK, Sheila. Bexiga: cotidiano e trabalho em suas interfaces com a cidade (1906-1931). Tese de Doutorado em Arquitetura e Urbanismo. Faculdade de Arquitetura e Urbanismo Universidade de São Paulo. 2016. São Paulo/SP.

SELDIN, Claudia. Da capital de cultura à cidade criativa: resistências a paradigmas urbanos sob a inspiração de Berlim. Tese de Doutorado em Arquitetura e Urbanismo. Faculdade de Arquitetura e Urbanismo - Universidade Federal do Rio de Janeiro. Rio de Janeiro/RJ. 2015. 225p.

YUDICE, George. A conveniência da cultura. Belo Horizonte: Ed. UFMG, 2005.

Original recebido em: 04 de novembro de 2019

Aceito para publicação em: 05 de julho de 2020

Simone Luci Pereira

Pesquisadora do CNPq - Bolsista de Produtividade em Pesquisa. Mestre em História e Doutora em Ciências Sociais - Antropologia pela

PUC/SP. Pós-Doutora em Comunicação. Pós-Doutora em Ciencias Sociales. Niñez y Juventud. Pós-Doutora em Música. Participa da rede internacional de investigação do Grupo de Trabalho CLACSO

Juventudes y Infâncias en América Latina desde 2015.

Professora/Pesquisadora do PPG Comunicação (Mestrado e Doutorado) da Universidade Paulista - UNIP, onde coordena o URBESOM (Grupo de Pesquisa em Culturas urbanas, Música e Comunicação).

Coordenadora do Grupo de Pesquisa "Comunicação e Culturas Urbanas" da INTERCOM (2017-2020). Vice-presidente da IASPM-LA (Associasión internacional para el estudio de la musica popular - Rama Latinoamericana) (2018-2020). https://orcid.org/0000-0002-7412-2129 
Milena Signor Avelar

Graduada em Relações Públicas (UMESP). Mestre em Comunicação

(Universidade Paulista - UNIP), tendo contado com Bolsa CAPES-

PROSUP. Pesquisadora do URBESOM (Grupo de Pesquisa em Culturas

Urbanas, Música e Comunicação) vinculado ao PPG Comunicação da

UNIP.

\section{@®®@}

Esta obra está licenciada com uma Licença

Creative Commons Atribuição-NãoComercial-CompartilhaIgual 4.0 Internacional 